\title{
„MASSENPSYCHOLOGIE” BEI DEN JUNGHEGELIANERN
}

Wir haben uns heute so sehr an die Tatsache gewöhnt, in einer Massengesellschaft zu leben, daß es uns schwer fällt, die besonderen Gefühle, die das Stichwort „Masse” jahrzehntelang ausgelöst hat, nachzuempfinden. Das „tiefe Erschrecken vor dem Auftreten der Massen auf der Bühne der Weltgeschichte" 1 ist inzwischen abgeklungen und einer sachlicheren Einstellung zu den Problemen der modernen Gesellschaft gewichen. Dennoch erfreuen sich, abgesehen von der nun schon beinahe legendären „Psychologie der Massen” des französischen Gelehrten Gustave Le Bon, solche einseitigen Darstellungen wie José Ortega y Gassets „Aufstand der Massen” noch einer großen Verbreitung, ${ }^{2}$ so daß es nicht ganz belanglos sein dürfte, sich zu vergegenwärtigen, welche Ansichten ursprünglich über den Charakter der Massen bestanden haben und welche Traditionen sich hierfür anführen lassen.

Ebenso wie das soziale Phänomen der Massen ist die Massenpsychologie eine Erbschaft des i 9. Jahrhunderts an das zwanzigste gewesen und von diesem lange Zeit als eine Art „unbewältigter Vergangenheit" mitgeschleppt worden. Bereits während des 19. Jahrhunderts war angesichts der sozialen Veränderungen, von denen die europäische Gesellschaft erfaßt worden war, wiederholt die Befürchtung geäußert worden, daß die sittlichen Grundlagen der Kultur in Gefahr seien. Das Entstehen großer Menschenansammlungen, die gleichermaßen Ausdruck der Bevölkerungszunahme als der Industrialisierung waren und die mit ihren unvermeidlichen Begleiterscheinungen physischen und moralischen Elends zeigten, wie wenig die alte Gesellschaftsordnung darauf vorbereitet war, die neuen

1 R. König, „Masse”, in: Soziologie (Fischer Lexikon ro), Frankfurt a.M. I958, S. I66. 2 Allein in rowohlts deutscher enzyklopädie hat diese Schrift von Januar 1956 bis März I 957 eine Auflagenhöhe von 90000 Exemplaten erreicht. Kritisch über Ortega y Gasset und die gesamte Massenpsychologie seit Le Bon handelt K. Baschwitz, Du und die Masse, 2. Aufl., Leiden 195 I. 
Aufgaben zu meistern, war in der Tat geeignet, einen tödlichen Gegensatz zu dem bisherigen Lebensgefühl zu bilden. Eine Kultur, die in Persönlichkeit und Individuum ihre höchsten Maßstäbe hatte und die sich zu einem intellektuell anspruchsvollen Bildungsideal bekannte, mußte das Vordringen einer zahlreichen Klasse von Wesen, die weder Persönlichkeit noch Individualität oder Bildung besaßen, für einen Einfall von Barbaren ansehen, dessen ungezähmter Wucht kein Bollwerk gewachsen sein würde. Das einzige Kennzeichen jener Bevölkerungsschichten, die sich zusehends auf dem Boden der Gesellschaft ansammelten und das überkommene Sozialgefüge von unten her zu durchbrechen begannen, konnte nur das ihrer unübersehbaren Menge sein; sie bildeten eine Masse und als solche waren sie eine Macht. Der Eindruck ihrer Stärke war so zwingend, daß den Verteidigern des alten, traditionsgebundenen Zustandes vielfach nur die schwache Hoffnung blieb, durch geschicktes Eingehen auf die Psyche der Massen wenigstens die Galgenfrist der europäischen Kultur zu verlängern. Damit hatte die Stunde der Massenpsychologie geschlagen.

In ihrem Leitspruch: „Die Massen sind so etwas wie die Sphinx der antiken Sage: man muß die Fragen, die ihre Psychologie uns stellt, lösen oder darauf gefaßt sein, von ihnen verschlungen zu werden", vereinigte sie sowohl Aufgabe als auch Selbstrechtfertigung und mit dem Bewußtsein ihrer Bedeutung trat sie an das Krankenbett des sterbenden Jahrhunderts. Es ist Gustave Le Bons Buch „Psychologie der Massen" gewesen, das, I895 erschienen, eine erste zusammenhängende Analyse des Phänomens Masse versuchte und das mit seinen pessimistischen Ergebnissen auf lange Zeit die Vorstellungen des Publikums prägte. Es hat seinen Lesern eine Theorie vermittelt, in der geschichtsphilosophische Spekulationen und psychologische Beobachtungen dazu dienten, den Massen als einer kulturzerstörenden Macht eine zyklisch wiederkehrende Aufgabe und einen minderwertigen Charakter zugleich zuzuschreiben. Ausgehend von der Ansicht, daß das Verhalten des Individuums von dem der Masse vollkommen verschieden sei, ist Le Bon zu der Meinung gelangt, daß der Mensch ,allein durch die Tatsache, Glied einer Masse zu sein, ... mehrere Stufen von der Leiter der Kultur" hinabsteige, da er ,in der Masse ... ein Triebwesen, also ein Barbar" sei. ${ }^{2}$ Den

1 G. Le Bon, Psychologie der Massen (Kröners Taschenausgabe, Bd. 99), Stuttgart 1953, S. 83 .

2 A.a.O., S. I9. 
Barbaren aber maß er die Rolle des Zerstörers alter, abgelebter Kulturen bei, und da er glaubte, Barbaren und Massen einander gleichsetzen zu dürfen, erwartete er von der vorauszusehenden Herrschaft der Massen das Ende der europäischen Kulturen. ${ }^{1}$

Sein Begriff der Masse enthielt drei verschiedene Gesichtspunkte: die Masse als eine psychologisch minderwertige Form menschlicher Gruppenbildung, ferner die Masse als eine in bestimmten historischen Augenblicken auftretende epochale Kraft und schließlich die Masse als eine zur unmittelbaren Herrschaft berufene soziale Gruppe. War es schon unbefriedigend, daß Le Bon den letzten Punkt als eine allgemeine Tatsache aufstellte und eines näheren Beweises nicht für bedürftig hielt, so machte sich der Mangel einer genauen historischen und soziologischen Begründung bei den ersten beiden Punkten noch nachteiliger bemerkbar. Obwohl es ihm gelungen war, mit seinem Begriff der „psychologischen Masse" 2 einen entwicklungsfähigen Ansatzpunkt zu finden, ist er mit seiner Theorie doch in eine Sackgasse geraten, weil er das Unbewußte, das er als konstituierendes Element der psychologischen Masse herausgestellt hatte, ${ }^{3}$ auf das engste mit den Rasseneigenschaften verbunden hat, so daß Massenbildung nur auf der Grundlage rassischer bzw. völkischer Zusammengehörigkeit möglich sein sollte. ${ }^{4}$ Unter dem Einfluß solcher geschichtsphilosophischen und rassenbiologischen Gedankengänge nahm Le Bons Massenbegriff ein oszillierendes, proteusartiges Aussehen an, das in seiner Gesamtheit keineswegs der sozialen Wirklichkeit entsprach, jedoch in seiner unbestimmten Vielseitigkeit vorzüglich dazu geeignet war, die Grundlage für das populäre Vorurteil über die Masse sowie über die angebliche Krise der Kultur und Gesellschaft abzugeben. Es ist den Sozialwissenschaften nur allmählich gelungen, diese Art der Massenpsychologie zu überwinden und durch eine „Sozialpsychologie des kollektiven Verhaltens" zu ersetzen. ${ }^{5}$ Die Breitenwirkung, die Le Bons Theorien heute noch haben, läßt sich schwer abschätzen; was ihnen jedoch an kritischen Einwänden entgegengestellt werden kann, hat Peter R. Hofstätter 1957 in seiner "Gruppendynamik" zum Ausdruck gebracht. ${ }^{6}$ Insbesondere hat Hofstätter

1 A.a.O., S. s f. und $179 \mathrm{ff}$.

2 A.a.O., S. 14. Vgl. dazu die positive Würdigung bei K. Baschwitz, a.a.O., S. 55 f.

3 G. Le Bon, a.a.O., S. I 5 .

4 A.a.O., S. Is und S. I35.

5 R. König, a.a.O., S. I7ı. Entsprechend J. Chr. Papalekas, „Masse”, in: Handwörterbuch der Sozialwissenschaften, Bd. VII, S. 222. Über die verschiedenen Standpunkte in der Massenpsychologie vgl. K. Baschwitz, a.a.O., S. Io ff.

6 P. R. Hofstätter, Gruppendynamik (rowohlts deutsche enzyklopädie $3^{8}$ ), Hamburg 1957. Úber Le Bon besonders S. 7 ff. Weniger leidenschaftlich, aber dennoch entschieden in seiner Kritik an Le Bon ist K. Baschwitz, a.a.O., S. I I ff. und passim. 
auf den sozialpsychologischen Hintergrund, vor dem sich die Massenpsychologie in ihrer ideologischen Form entfaltet hatte, hingewiesen, nämlich auf die gesellschaftliche Desintegration, von der ausgangs des 19. Jahrhunderts nicht zuletzt die Intellektuellen betroffen worden seien. Es sei eine „Vereinsamung der Intellektuellen” bewirkt worden, aus der heraus die massenpsychologische Ideologie als ein Versuch der Selbstrechtfertigung der an den Rand der sozialen Entwicklung abgedrängten Individuen entstanden sei. ${ }^{1}$

Sobald nun nach dem Beispiel Hofstätters die Massenpsychologie nicht als eine zufällige, sondern als eine aus dem Zustand der Gesellschaft um $1900 \mathrm{zu}$ erklärende Erscheinung aufgefaßt wird, ist es naheliegend zu fragen, wie sich den Zeitgenossen der voraufgegangenen Jahrzehnte der Wandel der sozialen Verhältnisse dargeboten hat und ob schon früher Anlaß bestanden hat, dem Phänomen Masse größere Aufmerksamkeit zu schenken. Denn das Krisengefühl, das sich bei Le Bon mit der Stimmung des fin de siècle verbunden hatte, war schon früheren Generationen vertraut gewesen und hatte sich insbesondere während der politischen und sozialen Spannungen der Vormärzzeit geäußert. Die soziale Emanzipationsbewegung, deren Erfolg für Le Bon offenkundig geworden war, reicht in ihren Anfängen, zumal was ihre ideellen Grundlagen betrifft, bis in die erste Hälfte des 19. Jahrhunderts zurück und ist bereits damals Anlaß zu kritischen Erörterungen gewesen. Zu denjenigen, die die Krise der sozialen und geistigen Daseinsform des Menschen zwischen 1830 und r 848 handgreiflich empfunden und zum Ausdruck gebracht haben, gehörten in Deutschland die Junghegelianer, die zich ganz der Vorstellung hingegeben hatten, in einer Zeitenwende zu leben und an dem Werden des Neuen gestaltend mitzuwirken. ${ }^{2}$ Gesellschaftlich wegen ihrer oppositionellen Ansichten zu einem Außenseiterdasein verurteilt, fanden sie sich bereits in der Rolle des ,vereinsamten Intellektuellen", der die Vereinsamung jedoch nur hinsichtlich der alten, bestehenden Gesellschaft anerkannte und ansonsten vorgab, die Zukunft auf seiner Seite zu haben. Die teilweise selbstgewählte, teilweise aufgezwungene Distanz zur geltenden Gesellschaftsordnung bot den Junghegelianern die Gelegenheit, ihr Talent zur schonungslosen Zeitkritik zu beweisen, und es soll nun Aufgabe der folgenden Unter-

${ }^{1}$ P. R. Hofstätter, a.a.O., S. ı f.

2 Die Bedeutung der Junghegelianer für die Geistesgeschichte des I9. Jahrhunderts ist in größerem Zusammenhange nachgewicsen worden von K. Löwith, Von Hegel zu Nietzsche. Der revolutionäre Bruch im Denken des I9. Jahrhunderts, 3. Aufl., Stuttgart r953. Über den Gang der junghegelianischen Bewegung unterrichtet die Darstellung bei A. Cotnu, Karl Marx und Friedrich Engels. Leben und Werk, Bd. 1, Berlin I954. 
suchungen sein zu zeigen, in welcher Weise das Phänomen Masse, das damals noch in einer elementaren, wenig durchorganisierten Form existierte, in diese Zeitkritik Eingang gefunden hat.

\section{II}

Die engen Beziehungen, die zwischen dem Denken der Junghegelianer und dem System der Hegelschen Philosophie bestanden haben, lassen es wünschenswert erscheinen, zunächst die Ansichten Hegels über die Masse zu untersuchen und die Frage zu prüfen, inwiefern vielleicht schon hier der spätere Massenbegriff vorgezeichnet worden ist. Aus Le Bons Theorien war zu ersehen gewesen, daß sich die Massenpsychologie eine recht komplexe Vorstellung von ihrem Gegenstand gebildet hatte. Sie hatte drei Dinge miteinander verknüpft: die negativen psychologischen Erkenntnisse über das menschliche Verhalten in Gruppen mit der Beobachtung von dem erfolgreichen Aufstieg einer zahlreichen sozialen Klasse und mit der Vermutung einer besonderen historisch-politischen Bedeutung dieser Klasse. Den Hintergrund für diese Kombination hatte das Krisengefühl der spätbürgerlichen Gesellschaft gebildet, das jedoch in dieser Form für die Anfänge des 19. Jahrhunderts, für die Zeit Hegels, noch nicht vorausgesetzt werden darf. Vielmehr ist das Selbstbewußtsein der damaligen Gesellschaft trotz der revolutionären und kriegerischen Erschütterungen, die jener Epoche für Jahrzehnte das Gepräge gegeben hatten, ungebrochen geblieben und hat ernsthafte Zweifel weder an der Gegenwart noch an der Zukunft Europas zugelassen. Das gilt auch von Hegel, dem zwar jeder leichtfertige Optimismus fremd gewesen ist, der aber dennoch auf die in der Geschichte waltende Vernunft vertraut und den beharrlichen Fortschritt der Menschheit für sicher gehalten hat. Er hat den Zustand seiner zeitgenössischen Gesellschaft nicht als krisenhaft empfunden, sondern ihren inneren Zusammenhang als dauerhaft und fortbildungsfähig geschildert. ${ }^{1}$

Allerdings sind ihm die Probleme, die der Gesellschaft in Deutschland auf der Übergangsstufe zu neuen sozialen und wirtschaftlichen Lebensformen anhafteten, nicht verborgen geblieben. Unabhängig davon, daß er wegen der individuell verschiedenen natürlichen und sozjalen Voraussetzungen die Ungleichheit unter den Menschen als eine zwangsläufige Gegebenheit erk]ärte, ${ }^{2}$ hat er mit großem Nach-

1 G. Lukàcs, Der junge Hegel, Berlin 1954, S. 420 f., bemerkt, daB Hegel noch nichts vom Klassenkampf geahnt und "die bürgerliche Gesellschaft als etwas Einheitliches" aufgefaßt habe.

${ }^{2}$ G. W. F. Hegel, Grundlinien der Philosophie des Rechts, 4. Aufl, hrsggb, v. J. Hoffmeister, Berlin 1956, S. I 74 f. ( $(200)$; dazu P. Vogel, Hegels Gesellschaftsbegriff und seine geschichtliche Fortbildung durch Lorenz Stein, Marx, Engels und Lassalle (Kant-Studien, Ergänzungsheft Nr. 59), Berlin I925, S. 49 und 50. 
druck auf die Erscheinungen der Armut hingewiesen, die er als ein Nebenergebnis der arbeitsteiligen, industriellen Gesellschaft deutete. ${ }^{1}$ Die Opfer dieser Armut bildeten in seinen Augen den „Pöbel”, der durch das „Herabsinken einer großen Masse unter das Maß einer gewissen Subsistenzweise" hervorgerufen wurde, ${ }^{2}$ der aber noch nicht - etwa im Sinne des späteren Proletariats - die Eigenschaft eines besonderen Standes innerhalb der Gesellschaft besaß. ${ }^{3}$ Denn Hegel hatte nur die drei Stände der Bauern, der Handel- und Gewerbetreibenden und der Beamten gelten lassen, ${ }^{4}$ neben denen der Pöbel gleichsam eine Ausnahmeerscheinung war, die freilich dank der, auch von Hegel erkannten, Eigenarten der bürgerlich-kapitalistischen Gesellschaft alle Aussichten hatte, zu einer ständigen Erscheinung zu werden. ${ }^{5}$ Es ist Hegel nicht gelungen, die Masse der deklassierten Menschen, deren Existenz ihm offenkundig war, in sein Schema der bürgerlichen Gesellschaft einzugliedern; er hat die soziale Frage nicht $z u$ lösen gewußt ${ }^{6}$ und dadurch die von ihm als System der Bedürfnisse beschriebene bürgerliche Gesellschaft zu einem großen Teil in ein System der unbefriedigten Bedürfnisse umschlagen lassen.

Es kann zwar niemandem ein Vorwurf daraus gemacht werden, daß er für verwickelte soziale Fragen keine Patentlösung anzubieten wußte, aber im vorliegenden Falle bleibt dennoch Anlaß zu einigen kritischen Bemerkungen. Denn wenn auch Hegel die Lage des verelendeten Pöbels zu würdigen versucht und sie der helfenden Fürsorge von Staat und Gesellschaft empfohlen hat, ${ }^{7}$ so ist es doch im Hinblick auf die spätere Massenpsychologie bedeutungsvoll, daß er diesen massenhaft auftretenden Pöbel als ein außerhalb der Gesell-

1 Hegel, a.a.O., S. 200 f. ( $\$\lceil 243$ ff.).

2 A.a.O., S. 201 ( $\$ 244)$.

3 W. Conze, „Vom 'Pöbel' zum 'Proletariat'. Sozialgeschichtliche Voraussetzungen für den Sozialismus in Deutschland", in: Vierteljahresschrift für Sozial- u. Wirtschaftsgeschichte, Bd. XLI (1954), S. 333 ff. Über den Pöbel als eine „unterständische” Erscheinung besonders $\mathrm{S} .336 \mathrm{f}$.

4 Hegel, a.a.O., S. I 76 f. ( $\$ 203$ ff.). Er hat nicht von einem Stand der Beamten, sondern vom ,allgemeinen Stand" gesprochen $(\oint 205)$, diesen jedoch des näheren als einen „dem Dienst der Regierung sich widmenden Stand" beschrieben (S. 264, $\$ 303); vgl. dazu P. Vogel, a.a.O., S. 29, und F. Rosenzweig, Hegel und der Staat, München und Berlin I920, Bd. II, S. I 21 .

5 Vgl. Hegel, a.a.O., S. 201 ( $\$ 245)$.

Vgl. P. Vogel, a.a.O., S. 54; G. Lukacs, a.a.O., S. 42 I; K. Löwith, a.a.O., S. 290 f. F. Rosenzweig, a.a.O., Bd. II, S. I 25 f., glaubte, in Hegels Hinweis auf die überseeische Kolonisation eine Lösung der sozialen Frage im Sinne einer „Umwandiung des industriellen Menschenüberschusses in bäuetliche Kolonisten" sehen zu dürfen; er hat dabei ebenso wie Hegel verkannt, daß diese Umwandlung ihrerseits ein kaum zu lösendes sozialpädagogisches Problem darstellt.

7 Hegel, a.a.O., S. I 99 f. (\$\$24I f.), sowie S. 205 f. $(\$ 293)$. 
schaftsordnung stehendes Phänomen empfunden hat. Dadurch ist ein unausgeglichenes Gegenüber von sozial integrierten und nichtintegrierten Menschengruppen geschaffen bzw. anerkannt worden, das sich in der Einschätzung, die die verschiedenen Gruppen einander wechselseitig zuteil werden ließen, nachteilig bemerkbar machen mußte. Es bestand nämlich die Gefahr, daß der nichtintegrierte Pöbel bei fortschreitender Zuspitzung der sozialen Beziehungen von den Anhängern der bedrohten Ordnung als feindliches Element, das das gesellschaftliche Gefüge von außen her zu zerstören suche, bezeichnet und damit zum Ziel heftiger Abwehrreaktionen gemacht werden würde, wie sie in der späteren Massenpsychologie tatsächlich aufgetreten sind. Vor solchen Fehlurteilen ist Hegel selbst noch bewahrt geblieben, weil ihm die Gesellschaftsordnung seiner Zeit nicht als krisenhaft erschienen ist, aber unter entsprechend veränderten Verhältnissen wäre es nur ein Schritt gewesen von der sachlichen Feststellung, die die Existenz eines massenhaften, desintegrierten Pöbels zur Kenntnis nahm, bis zur Behauptung, daß diese desorganisierte Masse die bestehende Gesellschaftsordnung umzustürzen drohe, und es würde dann keine Mühe gekostet haben, den furchtbar gewordenen Pöbel zum Sündenbock der zahlreichen sozialen Nöte und Ängste zu machen. Auf diese Weise hat sich bei Hegel ungewollt der Gegensatz, der auf Jahrzehnte hinaus die bürgerlichkapitalistische Gesellschaft in Spannung halten sollte, aufgetan und einen zunächst noch verborgenen Ansatzpunkt für die Massenpsychologie geschaffen.

Die ständische Gliederung, die Hegel der bürgerlichen Gesellschaft unterlegt hat, ist ihm auch für die politische Organisation des Staates von Bedeutung gewesen. Im Gegensatz zu allen egalitären Ideen hat er daran festgehalten, daß der Staat nicht die Summe der ihm angehörenden Staatsbürger sei, sondern ein in sich gegliedertes Ganzes, in dem die Stände als ,vermittelndes Organ ... zwischen der Regierung überhaupt einerseits und dem in die besonderen Sphären und Individuen aufgelösten Volke andererseits" stünden. ${ }^{1}$ Sie sollten in dieser Stellung bewirken, „daß die Einzelnen nicht zur Darstellung einer Menge und eines Haufens, zu einem somit unorganischen Meinen und Wollen, und zur bloß massenhaften Gewalt gegen den organischen Staat kommen".2 Dementsprechend hat Hegel die Idee des allgemeinen, gleichen Wahlrechts abgelehnt ${ }^{3}$ und die Berufung der politischen Stände eng mit der Beschaffenheit der sozialen Stände verknüpft, die dadurch „,in Beziehung auf den Staat zur Existenz”

1 A.a.O., S. $263(\$ 302)$.

2 Ebda.

3 A.a.O., S. $265(\$ 303)$ und S. $267(\$ 308)$. 
kämen und „einen politischen Zusammenhang” erhielten. ${ }^{1}$ Das hatte zur Folge, daß in der Sphäre des Staates ebensowenig wie im Bereich der Gesellschaft Platz für die unendliche Menge der einzelnen Menschen gewesen wäre und daß hier wie dort der Einzelne nur zählte, wenn er ,als Mitglied eines Allgemeinen zur Erscheinung” kam. ${ }^{2}$ „Die Vielen als Einzelne, was man gern unter Volk versteht, sind wohl ein Zusammen, aber nur als die Menge, - eine formlose Masse, deren Bewegung und Tun eben damit nur elementarisch, vernunftlos, wild und fürchterlich wäre". ${ }^{3}$

Mit diesen Worten hat Hegel eine Kritik der Masse ausgesprochen, die der späteren Massenpsychologie in der Aussage nahe kommt, sich von ihr aber dadurch unterscheidet, daß die Masse nur als Möglichkeit erwähnt wurde. Sie war als eine politische Kraft noch nicht Wirklichkeit geworden, war aber trotzdem theoretisch denkbar und mußte bei der Anwendung falscher politischer Grundsätze (Hegel hat dazu sowohl die rationalistisch-egalitären als auch die irrationalromantischen Ideen gerechnet) unvermeidlich werden. Es war eine Frage der weiteren geschichtlichen Entwicklung, ob die hier formulierte Kritik der Massen ein greifbares Objekt finden und damit aus einem theoretischen Urteil zu einem Leitsatz praktischen Verhaltens werden würde. Solange die von Hegel vertretene Überzeugung herrschte, daß weder Staat noch Gesellschaft im Zustande der Desorganisation seien, konnte die verelendete soziale Masse als eine bedauerliche Erscheinung am Rande der bürgerlichen Wohlanständigkeit geduldet und die politische Masse als Ausgeburt abwegiger Theorien verachtet werden. Sobald sich aber dem aufmerksamen Zeitgenossen die Erkenntnis aufdrängte, daß die Masse nicht nur existent sei, sondern unaufhaltsam der Herrschaft entgegenstrebe, „da unvorsichtige Hände allmählich alle Schranken, die jene zurückhalten konnten, niedergerissen haben", ${ }^{4}$ hatte die Massenkritik ihr Objekt gefunden und konnte ihre Urteile in einer bis dahin ungewohnten Weise aktivieren.

Wie schon bei der Analyse der bürgerlichen Gesellschaft hat Hegel auch bei der Beschreibung der Staatsstruktur die Masse zwar nicht übersehen, jedoch als eine abnorme Erscheinung außerhalb seines Ordnungsschemas gelassen. Er hat sie nicht in sein System integriert und damit der Gefahr ausgesetzt, als quantité négligeable der kritischen Verachtung all jener zu verfallen, die ihre Existenz im

- A.a.O., S. $26_{3}\left(\$_{301}\right)$ und S. $267(\$ 308)$; vgl. F. Rosenzweig, a.a.O., Bd. II, S. 154 ff.

2 Hegel, a.a.O., S. $265(\$ 303)$.

3 Ebda.

4 G. Le Bon, a.a.O., S. 6. 
Sinne des Systems gerechtfertigt wußten. Diese Gefahr war um so größer, als Hegel die Begriffe „Pöbel”, „Menge” oder „Masse” nicht wertneutral, sondern gleichsam als negative Kontrastbegriffe zu den positiven Elementen seiner Staats- und Gesellschaftslehre verwandt hat. Sie konnten jederzeit von den Vertretern einer Zeitkritik, die sich gegen die Entwicklung zur modernen Massengesellschaft wandte, aufgegriffen und zur Abwertung sozialer Gruppen eingesetzt werden. Diese Wendung mußte insbesondere drohen, sobald der Bildungsund Wissensstolz, der eine der stärksten Eigenschaften der Hegelschen Philosophie war, mit seinen selbstbewußten Ansprüchen in Gegensatz zu der Wirklichkeit geriet und dadurch der Versuchung ausgesetzt wurde, das wirkliche Geschehen wegen seiner Unvereinbarkeit mit den philosophischen Überzeugungen als Ergebnis wissensfeindlicher, dem geistigen Fortschritt abgeneigter Mächte zu verwerfen.

Es ist gezeigt worden, daß Hegel den Begriff der sozialen und der politischen Masse bereits gekannt hat. Den ersteren hat er auf eine in der bürgerlichen Gesellschaft entstehende Schicht bezogen und dadurch konkretisiert; den zweiten hat er nur als eine theoretische Möglichkeit benutzt, die auf keinen Fall praktische Wirklichkeit werden dürfe. Da er aber diese zweite Art der Masse in enge Verbindung mit den egalitären, demokratischen Ideen gebracht hat, war auch hier schon der konkrete Bezugspunkt für eine Aktivierung des Begriffs weitgehend gegeben. Was bei Hegel noch fehlte, das war die psychologische Masse, d.h. die Vorstellung, daß die Masse ein Phänomen sei, das jenseits aller sozialen und politischen Bedingungen auftreten und jeden einzelnen unterschiedslos erfassen könne. Ebensowenig hat er erwartet, daß die Masse - gleichgültig in welcher Form - zu einer epochalen Erscheinung werden könnte, denn solch eine Desorganisation der menschlichen Gesellschaft hatte er, der den Grundsatz verkündete, „daß die Vernunft die Welt beherrscht”, ${ }^{1}$ nicht in Betracht gezogen.

\section{III}

Der eigenartige Zustand der politischen und sozialen Verhältnisse in Deutschland während der Vormärzzeit, der zwischen Stagnation und Dynamik schwankte, brachte es mit sich, daß die Hegelsche Philosophie sich nach dem Tode ihres Schöpfers (183I) zunächst am stärksten auf religionsphilosophischem Gebiete auszuwirken be-

1 G. W. F. Hegel, Vorlesungen über die Philosophie der Weltgeschichte, 3. Auf., Bd. I, hrsggb. v. G. Lasson (Philosophische Bibliothek, Bd. I7I a), Leipzig 1930, S. 4. 
gann. ${ }^{1}$ Anders als in den Bereichen von Staat und Gesellschaft, wo den Ansätzen einer neuen Entwicklung der sichtbare Durchbruch nicht gelingen wollte, befand sich das geistige Leben in einer inneren Bewegung, die von den Zeitgenossen bereits gespürt wurde und die sich für Religion und Theologie als besonders folgenreich erweisen sollte. Eine philosophisch begründete Kritik, vertreten von der jungen Generation unter den Schülern Hegels, wandte sich mit zunehmender Leidenschaft gegen die historischen und dogmatischen Grundlagen des Christentums und schuf damit die Voraussetzungen für den Atheismus, der als wesentlicher Bestandteil in den marxistischen, sog. wissenschaftlichen Sozialismus übergegangen ist. Diese kritische Bewegung berührte anfänglich weder Staat noch Gesellschaft und ließ die Ansätze einer Analyse des politisch-sozialen Zustandes, die Hegel herausgearbeitet hatte, unbeachtet, so daß erst das Auftreten von Karl Marx in den I 840-er Jahren eine dauerhafte Wiederaufnahme dieser Traditionen bedeutete.

Bis dahin hatten sich die Junghegelianer in sichtbarer Entfernung von den sozialen Vorgängen ihrer Zeit gehalten. Sie lebten als Theologen oder Philosophen ganz ihrer Wissenschaft und kamen nur allmählich mit den modernen Gesellschaftstheorien in Berührung. Gleichzeitig entstanden in ihrer Mitte verschiedene, z.T. landschaftlich gesonderte Gruppen, die im allgemeinen nur unregelmäßige Verbindungen untereinander aufrechterhielten. Als ein Kreis von selbstbewußter Eigenart und Geschlossenheit erwies sich die schwäbische Fraktion der Junghegelianer, deren bekannteste Mitglieder um I 840 David Friedrich Strauß und Friedrich Theodor Vischer waren. Der Briefwechsel zwischen diesen beiden Männern, von denen Strauß seit seinem 1835 erschienenen kritischen „Leben Jesu” eine Berühmtheit unter den Gelehrten war, gewährt einen lebendigen Einblick in die Gedankenwelt dieser Gruppe und gibt über ihre Haltung zu dem Phänomen Masse einigen Aufschluß. Letzteres allerdings nur insofern, als die Masse hier kaum in begrifflich klar umrissener Weise erwähnt wird. Gelegentlich hat sich zwar Vischer, zweifellos der lebhaftere und tatkräftigere der beiden Freunde, voller Unmut vernehmen lassen, er habe schon lange gewußt, „daß die Masse schlecht ist", ${ }^{2}$ aber in dem gegebenen Zusammenhange ist der Begriff zu allgemein und gestaltlos geblieben, als da $\beta$ aus ihm weitere Schlüsse gezogen werden könnten. Nur soviel sei erwähnt, daß Vischer zu dieser Masse einige seiner Bekannten rechnete, von denen er sich in dem Bemühen, die württembergischen Buchhändler durch

1 Allgemein dazu K. Löwith, a.a.O., S. 78 ff., und A. Cornu, a.a.O., S. I 23 ff.

2 Briefwechsel zwischen Strauß und Vischer, hrsggb. v. A. Rapp, Bd. I, Sturtgart 1952, S. 77: Vischer an Strauß (5. Jan. 1839). 
eine gemeinsame Aktion zu einer gerechteren Berechnung der Preise für aus dem Ausland bezogene Bücher zu zwingen, im Stich gelassen fühlte. ${ }^{1}$

Sehr viel stärker ist der individualistische Standpunkt bei Strauß hervorgetreten. Seinem Wesen nach ein zur Selbstisolierung neigender Privatgelehrter, den zeitweilige trübe Stimmungen bis zum Lebensüberdruß treiben konnten, ${ }^{2}$ bekannte Strauß nach den Erfahrungen des Revolutionsjahres $I 848$, in dessen Trubel er wider Willen und nicht ohne Drängen seines Freundes Vischer geraten war, mit aller Entschiedenheit, daß er die Entfesselung der Massen verabscheue und vollends deren Herrschaft nicht ertragen könnte. ${ }^{3}$ Mit dem Mute zur Subjektivität hat er betont, daß er alles, was zu solch einer Herrschaft führe, hasse, wie nie zuvor etwas anderes, „weil mir nie etwas mich so absolut Negierendes entgegengetreten war". ${ }^{4}$ Voller Selbsterkenntnis bezeichnete er sich als einen „Epigonen jener Periode der Individualbildung . . ., deren Typus Goethe bezeichnet", und nahm für sich in Anspruch, die ,,jetzige Weisheit auf allen Gassen" verachten zu dürfen; „odi profanum vulgus et arceo ist und bleibt mein Wahlspruch".s

Solche Auffassungen bedeuteten keinen Fortschritt gegenüber der Hegelschen Gesellschaftsanalyse und ließen lediglich erkennen, daß die Masse ohne Rücksicht auf nähere Definitionen als etwas Verwerfliches angesehen wurde, sei es nun, daß sie wegen ihrer tatenwidrigen Trägheit, oder sei es, daß sie wegen ihrer den individuellen Lebenskreis zerstörenden Gewalttätigkeit gescholten wurde. In gewissem Ausmaße neigten zu derartigen Anschauungen alle Junghegelianer, die im Vollgefühl ihrer persönlichen Bedeutung nur allzu schnell bereit waren, jede kritische Äußerung aus ihrer Umgebung als ein Zeichen für die Feindschaft der Masse gegen den fortschrittlichen Geist abtun zu dürfen.

\section{IV}

Besonders angelegentlich hatte sich Bruno Bauer dieses Mittels

1 A.a.O., S. $7^{2}$, Vischer an Strauß (4. Nov. $183^{8}$ ) : „Es ist niederträchtig, wie die Masse ist: alle meine Bekannten hier sind gleich empört über das Unrecht, keiner aber tut mit!" 2 A.a.O., S. I04, Strauß an Vischer (13 Nov. I 841): „Kann man nicht leben und weiß auch nicht zu sterben, so bleibt nur das Absterben bei lebendigem Leibe übrig. Das will ich, es ist ganz richtig."

${ }^{3}$ A.a.O., S. 224, Strauß an Vischer (24. Febr. 1849): „Unter russischem Despotismus könnte ich, zwar mit beschnittenen Flügeln, doch noch existieren, aber Massenherrschaft würde mich vernichten."

4 Ebda.

5 A.a.O., S. 2 r 3, Strauß an Vischer (13. Nov. 1848). 
der Selbstrechtfertigung bedient. Er war in seinen theologischen Forschungen über die Entstehung der Evangelien zu dem Ergebnis gelangt, daß diese schriftlichen Dokumente des Christentums ausschließlich menschlichen Ursprungs seien, deshalb als die veraltete Produktion eines vergangenen Zeitalters zu gelten hätten, und daß mit ihnen sowohl Theologie als auch Christentum und darüberhinaus jede Religion einem neuen, freien Geiste weichen müßten. ${ }^{1}$ Die Grundlegung solch einer selbstbewußten Geisteshaltung hielt sich Bauer in hohem Maße zugute, da er durch seine Forschungen wissenschaftlich bewiesen zu haben glaubte, daß das Christentum keine ewige, sondern nur eine historisch bedingte Erscheinung sei, deren Bedeutung hinfällig werde, sobald der menschliche Geist die ihr entsprechende Bewußtseinsform überwinde. Diesen Fortschritt erwartete er von seiner Gegenwart, die er in den Rang einer epochalen Zeitenwende erhob. Die Menschheit habe jetzt „eine neue Ära erreicht"; ${ }^{2}$ "der Kampf, der bevorsteht, ist der letzte", ${ }^{3}$ und die entscheidende Waffe werde dabei die Kritik der Religion sein, denn nur sie könne die geistige Selbständigkeit des Menschen gegen die Prätensionen einer transzendentalen Gottheit sicherstellen. „Die Kritik ist die Krisis, welche das Delirium der Menschheit bricht und den Menschen wieder sich selbst erkennen läßt”; "ohne durch das Feuer der Kritik gegangen zu sein, wird nichts in die neue Welt, die nahe herbeigekommen ist, eingehen können". 5

Bauer rechnete nicht mit einem kampflosen Übergang der Menschheit in die "neue Welt", und der Begriff Kritik bedeutete bei ihm mehr denn je Angriff und aktive Auseinandersetzung, mit dem Ziele, die Menschen aufzurütteln und zu selbstbewußtem Verhalten zu veranlassen. Aber dessenungeachtet sollte es sich um einen geistigen Kampf handeln, in dem der Sieg einer nach allen Seiten vollkommen entwickelten Theorie sich zwangsläufig und selbsttätig einstellen müsse, da die veraltete Wirklichkeit dem neuen Geist nicht standhalten könne. ${ }^{6}$ In diesem Sinne hatte er zunächst gemeint, daß der Anbruch des

1 Über Bauers Werdegang und Wirken bis 1849 vgl. die phil. Diss. von D. Hertz-Eichenrode, Der Junghegelianer Bruno Bauer im Vormärz, Berlin 1959.

2 B. Bauer, Rezension zu Kliefoth, "Einleitung in die Dogmengeschichte”, in: Anekdota zur neuesten deutschen Philosophie und Publicistik, Bd. II, Zürich und Winterthur I 843 , S. 196 .

${ }^{3}$ [B. Bauer], Die evangelische Landeskirche Preußens und die Wissenschaft, Leipzig I 840 , S. 6.

4 B. Bauer, Die gute Sache der Freiheit und meine eigene Angelegenheit, Zürich und Winterthur I 842, S. 204.

5 B. Bauer, Die Judenfrage, Braunschweig I 843 , S. 2.

6 Zum Problem von Theorie und Praxis bei Bauer s. D. Hertz-Eichenrode, a.a.O., S. 8 sf. und 93 f. 
neuen Zeitalters unmittelbar bevorstünde, aber unter dem Eindruck entgegengesetzter Erfahrungen mußte er dann zugestehen, daß es noch ungewiß sei, wann die Geschichte die ,neue Gestalt aller öffentlichen Verhältnisse" herbeiführen werde. ${ }^{1}$

Trotz seinem Vertrauen auf den gerechten Gang der Geschichte wurde Bauer von der Frage bewegt, weshalb der allgemeine Fortschritt so sehr verzögert worden sei. Es mußte eine Kraft geben, die sich der Verbreitung des neuen Geistes entgegenstemmte und die es verhinderte, daß die Wirklichkeit entsprechend der von der Kritik begründeten Theorie umgestaltet wurde. Diesen Widersacher des Geistes erkannte Bauer in der Masse, und zwar der „Masse in jenem Sinne, in welchem das Wort auch die sogenannte gebildete Welt umfaßt”. ${ }^{2}$ „In der Masse . . . ist der wahre Feind des Geistes zu suchen. Alle großen Aktionen der bisherigen Geschichte waren deshalb von vornherein verfehlt und ohne eingreifenden Erfolg, weil die Masse sich für sie interessiert und enthusiasmiert hatte". ${ }^{3}$ Sollte also ein Weg aus der Sackgasse, in die die geistige und politische Entwicklung um $\mathrm{I} 843$ geraten $\mathrm{zu}$ sein schien, gefunden werden, dann mußte auf Maßnahmen gesonnen werden, die nicht sogleich das Opfer eines verderblichen Enthusiasmus seitens der öffentlichen Meinung würden, sondern die den strengen Anforderungen des Geistes gerecht würden und von niemandem ohne eigene ernsthafte Anstrengungen ergiffen werden könnten.

Bei diesen Überlegungen zog Bauer auf seine Weise die Konsequenzen aus der Entwicklung der öffentlichen Meinung der voraufgegangenen Jahre. Als nämlich $184^{\circ}$ in Preußen durch den Tod Friedrich Wilhelms III., eines Monarchen, der nahezu 43 Jahre über sein Land geherrscht hatte, ein Thronwechsel eintrat, da wurde dies zu einem Ereignis, das vielfach die Hoffnung auf den Beginn einer neuen Epoche weckte. Der literarisch-politische Meinungsaustausch begann sich zu beleben, und insbesondere die Junghegelianer glaubten, ihre religions- und staatskritischen Ideen nun offener entwickeln zu dürfen. Sie waren dabei des guten Glaubens, dem allgemeinen Besten zu dienen und sich in Einklang mit den wohlverstandenen Intentionen des neuen Regiments zu befinden. Jedoch nach einigen tastenden Versuchen des jungen Königs und der Regierung, ein freundliches Verhältnis zu den erwachenden Kräften der öffentlichen

1 B. Bauer, Die gute Sache etc., S. 224 .

${ }^{2}$ [B. Bauer], „Neueste Schriften über die Judenfrage” [I], in: Allgemeine Literatur-Zeitung [ = ALZ], Heft I (1843), S. 2. Über Masse und Kritik vgl. D. Hertz-Eichenrode, a.a.O., S. IoI ff.

3 [B. Bauer], a.a.O., S. 3. 
Meinung herzustellen, sah sich die oppositionelle Pressebewegung zu Beginn des Jahres 1843 bereits wieder einem verschärften Druck. der Zensur ausgesetzt, da ihre politischen Anschauungen mit denen des Königs nicht zu vereinbaren gewesen waren. ${ }^{1}$ Bei dem Fehlen jeder Art von Organisation auf seiten der oppositionellen Kräfte genügten bereits die zensurverschärfenden Maßregeln, um die unerwünschten Bestrebungen in ihrer Wirkung zu beeinträchtigen, und gerade dieser leichte Sieg des alten Polizeistaates über seine Widersacher diente Bauer als Lehre dafür, daß mit einigen gesinnungstüchtigen, vom öffentlichen Beifall begleiteten Schlagworten nichts gewonnen sei und daß es ganz anderer Leistungen bedürfe, um zu bleibenden Resultaten zu gelangen. In diesem Zusammenhange ließ die Ahnungslosigkeit, mit der die zeitgenössische Publizistik über sein - Bauers - wissenschaftliches Werk und die darauf begründeten Theorien hinweggegangen war, in ihm die Überzeugung wachsen, $\mathrm{da} \beta$ die Stunde der geistigen und politischen Befreiung noch nicht geschlagen habe, daß vielmehr Ignorantentum und bewußte Selbsttäuschung das Geschehen beherrschten. Denn angesichts der Tatsache, daß die Theorie, die den Weg in die Zukunft wies, bereits vollständig entwickelt und bewiesen worden sei, konnte Bauer das Beharren auf nichtssagenden Phrasen nur als eine geistige Kraftlosigkeit bezeichnen, die durch ihr Scheinbekenntnis zum Gedanken des Fortschritts jeden wirklichen Fortschritt unmöglich mache. Die Summe all der retardierenden Elemente faßte er in dem Begriff Masse zusammen, der ihm zum Schlüsselwort für seine Zeitdiagnose wurde. Er bezeichnete damit einen geistigen Zustand, der sich in der bei allen Volksschichten sich offenbarenden Unfähigkeit, den tieferen Sinn der modernen wissenschaftlichen Bestrebungen zu erfassen, und in der ebenso sichtbaren Unwilligkeit, ernsthafte Versuche zur L'berwindung der derzeitigen politisch-sozialen Stagnation zu unternehmen, zeigte. Masse - das war Feindschaft gegen den Geist, Bewußtlosigkeit über den Charakter der Gegenwart, flacher Enthusiasmus für gehaltlose Phrasen, Unbeständigkeit in der Verteidigung von Meinungen und vor allen Dingen Verschwörung gegen die Bauersche Kritik.

Jedoch mit dieser letzteren Wendung glaubte Bauer bereits die Trennung der Gegensätze, die er als Voraussetzung des Fortschritts betrachtete, eingeleitet zu haben, denn es sei ein "großer Gewinn, wenn diejenigen, die die Freiheit zur Redensart . . . machten, in die

1 Vgl. hierzu W. Conze, "Staat und Gesellschaft in der frührevolutionären Epoche Deutschlands", in: Historische Zeitschrift, Bd. I86 (1958), S. I8f. 
Reihe der offenen Gegner der Freiheit zurückgeworfen werden. Die Frage, um die es sich handelt, wird damit vereinfacht, ihre große Bedeutung wird sichergestellt und ihre Entscheidung beschleunigt", d.h. der derzeitige Triumph der Masse sei nur eine vorübergehende Erscheinung und werde im gegebenen Augenblick dem Anbruch des neuen Zeitalters, dessen geistige Grundlegung in der Bauerschen Kritik enthalten sei, weichen müssen. Freilich, „wie lange die Übergangsperiode dauern wird, in der wir leben”, meinte Bauer, ,ist eine Frage, deren Beantwortung uns in dem Augenblicke, wo wir damit beschäftigt sind, die Macht, die die Tore der Zukunft verschlossen zu halten sucht, der Kritik zu unterwerfen, . . . ziemlich gleichgültig sein kann. In keinem Falle wird sie für uns beunruhigend sein ..." 2

Die Gewißheit, mit der Bauer trotz den zunächst noch ganz entgegengesetzten Tatsachen an den Sieg seiner Theorien glaubte, bezog er zu einem wesentlichen Teil aus dem Wissen um die Minderwertigkeit der Masse. Sie konnte nichts Bleibendes sein, im Gegenteil, sie deutete durch ihre Existenz die Haltlosigkeit der bestehenden Verhältnisse an ${ }^{3}$ und eröffnete die Aussicht auf einen Umschwung. Dieser Optimismus war allerdings das Ergebnis eines Wunschdenkens, das seine Berechtigung aus einer fortschrittsorientierten Geschichtsphilosophie herleitete und seine Wurzeln in dem Hegelschen Satze hatte, daß die Weltgeschichte ein ständiger „Fortschritt im Bewußtsein der Freiheit" sei. ${ }^{4}$ Ein solches Denken unterstellte dem historischen Geschehen eine zwangsläufige, unveränderliche Richtung, deren Vorhandensein dem Wissenden, wie das Beispiel Bauers zeigt, ein optimistisches Vertrauen in die Gerechtigkeit der Geschichte vermitteln konnte.

Wie in geistiger, so hat Bauer auch in sozialer Hinsicht das Phänomen der Masse als ein Zeichen der Krise bewertet. Er hat sich zwar vorzugsweise auf ideelle Tatbestände berufen, um den Epochencharakter seiner Zeit zu beweisen, aber gelegentlich konnten die sozialen Veränderungen selbst ihm nicht entgehen, und so lassen sich bei ihm in den Jahren I843 und I844 einige Ansätze einer Gesellschaftsanalyse

" [B. Bauer], „Neueste Schriften über die Judenfrage" [II], in: ALZ, Heft IV (1844), S. 13.

2 A.a.O., S. io.

3 Hirzel [Pseudonym für B. Bauer?], „Korrespondenz aus Zürich”, in: ALZ, Heft V (1844), S. 13: "Jede neue Bildungsstufe der Menschheit hatte immer das Extrem der Beschränktheit und Leerheit, welches die vorhergehende Bildung zu erzeugen im Stande war, zur Voraussetzung..."; vgl. dort auch S. 15.

4 G. W. F. Hegel, Vorlesungen über die Philosophie der Weltgeschichte, hrsggb. v. G. Lasson, 3. Aufl, Bd. I (Philos. Bibl. Bd. 171a), L.eipzig 1930, S. 40. 
finden, ${ }^{1}$ die, obwohl nur schwach entwickelt, geeignet sind, dem Begriff Masse eine genauere Beleuchtung zu geben.

Grundsätzlich hat sich Bauer der Terminologie Hegels angeschlossen und die Gliederung des Staates in Stände und das Bedürfnis als die Triebfeder der bürgerlichen Gesellschaft anerkannt. Jedoch hat er zugleich hervorgehoben, daß das für diese Gesellschaftsform kennzeichnende „egoistische Treiben" den Bestand der sozialen Ordnung bedrohe. „Gerade ihre Grundlage, das Bedürfnis, welches der bürgerlichen Gesellschaft ihr Bestehen sichert und ihre Notwendigkeit garantiert, setzt ihr Bestehen ständigen Gefahren aus, unterhält in ihr ein unsicheres Element und bringt jene in ständigem Wechsel begriffene Mischung von Armut und Reichtum, Not und Gedeihen, überhaupt den Wechsel hervor".2 Diese Unstetigkeit der Verhältnisse deutete Bauer als ein Anzeichen des allgemeinen Verfalls und des Entstehens der Masse, wobei er „die Masse als solche” als eine Erscheinung wertete, „die erst eintreten konnte, nachdem die spezifischen Unterschiede, in welchen sich die Gattung bisher dargestellt hatte, verblaßt waren. Sie ist der Verfall der Gattung in die einzelnen Atome, die Auflösung der besonderen Schranken, welche die Individuen bisher zwar trennten, aber auch verbanden und in eine mannigfaltige Beziehung setzten; sie ist ein bloß elementarischer Stoff, der Niederschlag einer zersetzten organischen Gestalt". ${ }^{3}$ Ihr Ursprung sei die Auflösung der alten ständischen Gesellschaftsordnung infolge der Aufkärung und der französischen Revolution - „die Masse ist das bedeutendste Erzeugnis der Revolution - der Niederschlag, der aus der Neutralisation der feudalen Gegensätze hervorging" 4 - und ihr Ergebnis sei das Auseinandergehen der ,gemeinsamen Standesinteressen in das reine Interesse, in die Unendlichkeit der konkurrierenden Interessen". ${ }^{5}$ Somit war die Masse in geistiger und sozialer Hinsicht eine Erscheinung des Verfalls, d.h. sie war nicht eine Ausnahme, sondern sie war das Charakteristikum der Zeit. Was bei Hegel noch für ein Phänomen am Rande einer festgefügten Ordnung gegolten hatte, das war nun zur beherrschenden Tatsache geworden. Allerdings kannte Bauer nicht die geringste Furcht vor der Masse, sondern vermerkte es mit selbstgefälligem Stolz, daß er in vollem Gegensatz zu dieser Entwicklung stand und persönlich

${ }^{1}$ Es ist wohl kein Zufall, daß um dieselbe Zeit sozialistische und kommunistische Theorien, aus Frankreich kommend, die öffentliche Meinung in Deutschland zu beschäftigen begannen. Überdies war I 842 Lorenz Steins bekanntes Buch „Der Sozialismus und Kommunismus des heutigen Frankreich. Ein Beitrag zur Zeitgeschichte" erschienen.

2 B. Bauer, Die Judenfrage, S. 8.

${ }^{3}$ [B. Bauer], „Die Gattung und die Masse”, in: ALZ, Heft X (r844), S. 43 f.

4 [B. Bauer], "Was ist jetzt Gegenstand der Kritik?", in: ALZ, Heft VIII (1841), S. 25.

5 [B. Bauer], "Die Gattung und die Masse”, a.a.O., S. 42. 
von ihr nicht mehr berührt wurde. ${ }^{1}$ Obwohl sein Werturteil über die Masse nicht minder abschätzend war als dasjenige späterer Massenpsychologen, so fehlte ihm doch noch die unbewußte und darum um so quälendere Angst vor der Macht der Masse. Seine fortschrittsgläubige Geschichtsphilosophie verlieh ihm ein optimistisches Lebensgefühl, das ihn davor bewahrte, sich einer intellektuell verbrämten Lust am Untergange hinzugeben. Sein individuelles Selbstverständnis beruhte auf der Annahme, daß seine atheistische Religionskritik den Grundstein für ein neues Zeitalter der Menschheitsgeschichte gelegt habe und daß die Zukunft den allgemeinen Sieg dieses Atheismus bringen werde. Seine Gegenwart war ihm deshalb nur ein Übergangsstadium, dessen Verderbtheit erkennen lasse, wie nahe bereits die ,neue Welt" herangekommen sei. Die Masse stellte in seinen Augen nicht den Träger des neuen Zeitalters dar, sondern das letzte, nicht mehr fortbildungsfähige Produkt der ablaufenden Epoche. Sie war nichts Neues und konnte auch nichts Neues schaffen; sie war das letzte Stadium des Alten.

Um so wissenswerter wäre es gewesen, wie die von Bauer in Aussicht gestellte neue Welt aussehen sollte. Jedoch in diesem Punkte mußten sich die Leser mit einigen unbestimmten Andeutungen begnügen, z.B. daß es sich ,um die Menschheit handelt”, daß die Menschheit ,alles in allem sein" solle, ${ }^{2}$ und daß "diejenige Weltform, welche die Kritik vorbereitet..., keine bloß rechtliche, sondern eine gesellschaftliche" sein werde. ${ }^{3} \mathrm{Da}$ Bauer jedoch die kommunistischen Sozialtheorien als Illusionen der Masse ablehnte, ${ }^{4}$ mußte der Charakter der neuen Gesellschaft trotz dem Hinweise auf die notwendige „Befreiung der bürgerlichen Heloten, welche täglich mit der Materie zu kämpfen haben", 5 recht ungewiß bleiben, zumal sich Bauer dem Verlangen nach weiteren Aufschlüssen mit der Bemerkung entzog, daß er als Kritiker nicht die Pflicht habe, sich „als Gesetzgeber bloßzustellen, sondern das Bestehende und die Versuche, die Kolli-

1 „Uns aber kann es nur freuen, wenn die Zahl der Gegner wächst . . . Wenn endlich alles sich gegen sic [die Kritik] verbindet - und dieser Zeitpunkt ist nicht mehr fern -, wenn die ganze zerfallende Welt sich zum letzten Ansturm um sie herum gruppiert, dann wird der Mut der Kritik und ihre Bedeutung die größte Anerkennung gefunden haben. Um den Ausgang kann es uns nicht bange sein." Hirzel [= B. Bauer?], „Korrespondenz aus Zürich", in: a.a.O., S. I 5 .

2 B. Bauer, Die gute Sache etc., S. 204.

3 [B. Bauer], ,Neueste Schriften über die Judenfrage” [II], in: a.a.O., S. 15.

4 Vgl. [B. Bauer], „Die Gattung und die Masse", in: a.a.O., S. 42 ff., und B. Bauer, Vollständige Geschichte der Parteikämpfe in Deutschland während der Jahre I 842-1 846, Charlottenburg I847, Bd. II, S. $76 \mathrm{ff}$., und Bd. III, S. 29.

5 B. Bauer, „Der christliche Staat und unsere Zeit”, in: Hallische Jahrbücher für deutsche Wissenschaft und Kunst, IV. Jahrg. (1841), S. 553. 
sionen desselben zu vertuschen, vielmehr zu charakterisieren, um der entscheidenden Gesetzgebung reinen Boden zu verschaffen". ${ }^{1}$

Nach allem bisher Gesagten wird das zusammenfassende Urteil über Bruno Bauers Massenpsychologie dahingehend lauten müssen, daß in ihr subjektive Eindrücke ohne ausreichende sozialkritische Begründung verallgemeinert worden sind. Die Aufmerksamkeit Bauers hat in erster Linie der geistigen Verfassung der Zeit gegolten, da er den Menschen einseitig als individuelles, geistiges Wesen verstanden hat. Deshalb ist sein Massenbegriff ideeller Art gewesen und konnte auf eine soziologische Konkretisierung verzichten. Seine schematische Ausdehnung auf die geistig-soziale Gesamtsituation der Jahre 1843-1 844 bewies Bauers Unvermögen, eine soziologisch differenzierende Sicht der gesellschaftlichen Verhältnisse zu bieten. Diese Schwäche hat sich im einzelnen nachteilig ausgewirkt, aber im allgemeinen hat sie Bauer davor bewahrt, seine Massenpsychologie mit einem speziellen sozialen Ressentiment zu belasten. Es ist auffallend, daß sich bei ihm in der Vormärzzeit keine Anzeichen für ein Klassenbewußtsein finden lassen; er dachte und handelte vielmehr als ausgesprochener Individualist, der sich vorsätzlich von der ihn umgebenden Gesellschaft absonderte, da sie seinem fortgeschrittenen Bewußtsein nicht mehr zu entsprechen schien. ${ }^{2}$ Aus der selbstgewählten geistigen Distanz verwischten sich ihm die Unterschiede innerhalb der bestehenden sozialen Ordnung, so daß nur eine gestaltlose Masse sichtbar blieb. Dank seinem Glauben an den Fortschritt und den Sieg des Geistes über die Masse konnte er ein positives Bekenntnis zur Krise seiner Zeit abgeben und sie als Rechtfertigung seiner Theorien ansehen. Er bemerkte dabei nicht, wie sehr das Irreale seiner Theorien davon zeugte, daß diese nicht die behauptete Überwindung, sondern selbst noch ein Ausdruck der Krise waren.

Nicht minder schwach sind die soziologischen Gesichtspunkte bei Max Stirner, einem eigenbrötlerischen Berliner Lehrer, der I 844 mit seinem Buch „Der Einzige und sein Eigentum” das junghegelianische Denken bis an die Grenzen des Logischen fortgetrieben hatte, zur Geltung gekommen. Von ihm ist die gedankliche Auflösung aller Abstraktionen und überpersönlichen Gewalten mit äußerster Konse-

1 [B. Bauer], „Neueste Schriften über die Judenfrage” [I], in: a.a.O., S. I 2.

2 B. Bauer, „Bekenntnisse einer schwachen Seele” in: Deutsche Jahrbücher für Wissenschaft und Kunst, V. Jahrg. (1842), S. 594: „Wenn die bestehenden Verhältnisse der Idee vollständig widersprechen, wo kann die Idee dann anders existieren als in dem reinen Selbstbewußtsein, welches aus der Verderbnis sich gerettet hat und die wahren Formen seiner Existenz als Ideale zunächst in sich trägt?" 
quenz durchgeführt worden, was bedeutete, daß nicht nur die Religion, sondern auch Staat und Gesellschaft in den Bann getan wurden, da sie die Bewegungsfreiheit des einzelnen Menschen einengten. ${ }^{1}$ Allerdings ist Stirner durch diese Ansichten nicht veranlaßt worden, für die Massen oder sonstigen antiindividualistischen Kräfte eine besondere Feindschaft zu hegen, da ihm der aktivistische Trieb, der die für richtig befundenen Vorstellungen so schnell wie möglich verwirklichen will, nur in geringem Maße eignete. Ihm galt jede Daseinsform, die den Einzelnen ohne Rücksicht auf dessen individualistische, egoistische Interessen in eine größere Gemeinschaft einordnete, als eine Verfehlung des Menschseins, und deshalb was es für ihn belanglos, eine eventuell vorhandene Masse noch mit besonderem Nachdruck zu kritisieren. Denn es hätte für ihn, der gerade diejenigen Formen menschlichen Zusammenlebens bekämpfte, deren Entfaltung allgemein als kulturelle Großtat verehrt wurde, keinen Sinn gehabt, sich mit Leidenschaft gegen eine Erscheinung zu wenden, die ohnehin als ein Ergebnis des Verfalls und der Unordnung angesehen wurde.

Die von Bruno Bauer und Max Stirner dargestellte Entwicklungslinie ist in ihren Resultaten nicht für alle Junghegelianer bezeichnend gewesen, vielmehr haben sich einige von ihnen unaufhörlich bemüht, in Verbindung mit der politischen und sozialen Wirklichkeit zu bleiben und einen unmittelbaren Einfluß auf sie auszuüben. $\mathrm{Zu}$ ihnen gehörte Arnold Ruge, der befähigteste Journalist unter allen seinen Gesinnungsgenossen. Er hatte bereits an der Tätigkeit der studentischen Burschenschaften teilgenommen, was ihm bei der ersten Demagogenverfolgung sechs Jahre Festungshaft eingetragen hatte. Dieses Mißgeschick hatte ihn jedoch in seiner Entschlossenheit, für den Fortschritt Deutschlands zu wirken, nicht beirren können, und in den 1830 -er Jahren wurde er einer der rührigsten junghegelianischen Schriftsteller. Seine Gedanken kreisten insbesondere um die Frage, wie den modernen Theorien in Staat und Gesellschaft Eingang verschafft werden könnte. Vorbehaltlos auf dem Standpunkt Strauß', Bauers und Ludwig Feuerbachs stehend - des letzteren philosophischpsychologisch begründete Analyse des Christentums verehrte er als eine besondere Leistung - beschäftigte er sich mit der Notwendigkeit, die große Mehrzahl der Menschen für diese neuen weltanschaulichen Positionen zu gewinnen. Er hielt es dabei für erforderlich, aus der engen Selbstgenügsamkeit des reinen Wissens auszubrechen und die

1 M. Stirner, Der Einzige und sein Eigentum, (Reclams Universal-Bibliothek) Leipzig [1893], S. 25 I ff., 364 f. 
gewonnenen Einsichten so weit wie möglich zu verbreiten, denn erst "die Bildung der Masse ist die Realisierung der Theorie". ${ }^{1}$ "Die Geburt der wirklichen, der praktischen Freiheit ist der Übergang ihrer Forderung auf die Masse", d.h. die praktische Freiheit werde nur geschaffen durch "die Bewegung der Massen im Sinne der Theorie".2

Diese Äußerungen geben zu verstehen, daß Ruge die Masse vorzugsweise als ein soziales Phänomen aufgefaßt hat und daß er ein positives Verhältnis zu ihr besessen hat, da sie ihm das Element war, das die modernen Theorien zur allgemeinen Anerkennung bringen müsse. Allerdings bleibt zu prüfen, was er unter dem Begriff Masse verstanden hat und inwieweit er mit diesem Ausdruck irgendwelche Wertung verbunden hat. Es zeigt sich bei näherem Zusehen, daß ihm die Masse im wesentlichen die große Menge der Menschen war, auf deren Aufklärung und damit auch sittliche Emanzipation die moderne Philosophie Bedacht nehmen müsse. „Das Denken der Masse ist die Befreiung der Masse", und der Erfolg dieses Aktes war durch die Gleichung gegeben: "Ist der Mensch ein denkendes Wesen, so ist es jeder Mensch". ${ }^{3}$ Demnach gehörten zur Masse nicht dumpfe, geistlose Wesen, sondern denkende Menschen, freilich noch im Stadium der Unkenntnis, aber dennoch befähigt, der neuesten theoretischen Erkenntnisse teilhaftig zu werden und durch Zustimmung deren Allgemeingültigkeit durchzusetzen. Die Masse war für Ruge das große Gewicht, das es galt, auf die eigene Seite herüberzuziehen, um über die bekämpften christlich-romantischen Staats- und Sozialtheorien zu obsiegen. Es war also eine positive Rolle, die er ihnen zutraute, jedoch war es Voraussetzung dafür, daß sie sich an die neueste Bildung anschlossen, was wiederum nur möglich war, wenn dies jeder einzelne in seiner Eigenschaft als denkender Mensch tat.

So aufschlußreich die Meinung, alle Menschen seien im Grunde genommen gleichbegabt und -befähigt, sein kann, so abstrakt erscheint sie jedoch, wenn sich mit ihr nicht die Einsicht verbindet, daß die Entwicklung dieser Gaben und Fähigkeiten in erheblichem Maße von der sozialen Situation des Menschen abhängig ist. Da Ruge für den Sieg seiner Sache auf den Beitritt der Massen technete, mußte die Berechtigung seiner Hoffnungen nicht zuletzt davon abhängen, inwieweit er die besondere Lage der Massen innerhalb der bestehenden Staats- und Gesellschaftsordnung berücksichtigte. In dieser Hinsicht läßt sich beobachten, daß er das soziale Schicksal der Massen

\footnotetext{
1 A. Ruge, Gesammelte Schriften, Mannheim I 846, Bd. III, S. 220 (aus: „Der Genius und die Geschichte... I 839 ").

2 A.a.O., I 847 , Bd. VI, S. I 33 und 134 (aus: „Studien und Erinnerungen aus den Jahren 1 843-45. Zweiter Teil").

3 A.a.O., I 847, Bd. VI, S. 248 f. (aus: „Der Patriotismus”).
} 
wohl wahrgenommen, aber dennoch nur für eine Art „Verwahrlosung" angesehen hat, deren Hauptnachteil darin bestand, daß sie den davon Betroffenen jegliche Teilnahme am geistigen und politischen Leben versagte. Dadurch wurden die Massen zu jener Region im sozialen Gefüge, „wo das Kommunalinteresse faktisch aufhört und das Individuum, rein auf das Leben angewiesen, aus aller geistigen Beteiligung herausfällt, - eine Verwahrlosung der Menschheit, deren Überwindung von der Zukunft zu erwarten ist, so gut die bisherige Geschichte die Sklaverei schon beseitigte". ${ }^{1}$ Bei einer späteren Gelegenheit hat sich Ruge nachdrücklich gegen die in Deutschland verbreitete Neigung gewandt, die Nöte der unterdrückten Gesellschaftsklassen gar nicht in Betracht zu ziehen bzw. deren Besserung nach dem Beispeil Hegels vom öffentlichen Bettel zu erwarten, ${ }^{2}$ und hat seinerseits Vermutungen über die Ursache der sozialen Gegensätze angestellt: „Offenbar liegt die Verwahrlosung der großen Massen in der Einrichtung unserer Gesellschaft, nach welcher nicht der Mensch und sein unverjährbares Recht, sondern das Eigentum das Prinzip ist". ${ }^{3}$ Über diese Feststellung ist er jedoch nicht hinausgediehen und die auf Gütergemeinschaft ausgehenden sozialreformerischen Theorien der Kommunisten hat er weit von sich gewiesen. $\mathrm{Da}$ er dadurch die Hoffnung, seine Theorien mit Hilfe der Massen zu verwirklichen, selbst untergraben hat, ist ihm nicht bewußt geworden. Er hat zwar auf der einen Seite die unbefriedigende Lage der Massen und ihren Ursprung in den Grundlagen der bestehenden Gesellschaftsordnung erkannt, aber er ist andererseits nicht $z u$ der Schlußfolgerung fortgeschritten, daß die in ihren Entfaltungsmöglichkeiten beschränkte Masse kaum imstande sein würde, sich die Vorzüge der steigenden Bildung anzueignen und dadurch im politisch-sozialen Geschehen mitspracheberechtigt zu werden. Die Theorie sollte von den Massen verwirklicht werden, aber wie die Massen in den Besitz dieser Theorie gelangen sollten, das blieb eine offene Frage.

Es darf angenommen werden, daß Ruge als Hegelianer zu einem groBen Teile auf die dem fortgeschrittenen Geiste zugeschriebene Kraft des Sich-selbst-Verwirklichens vertraut hat. Wie eng er dem Hegelschen Denken verbunden geblieben ist, gibt seine Gewohnheit zu erkennen, die Lage der Massen mit dem moralisierenden Begriff "Verwahrlosung" zu bezeichen. Darin ist enthalten, daß ihm das

1 A.a.O., I 846, Bd. III, S. 420 (aus: „Zur Kritik des gegenwärtigen Staats- und Völkerrechts. I 840").

2 A.a.O., I 846, Bd. IV, S. 309 f. (aus: „Über die intellektuelle Allianz der Deutschen und Franzosen ... I 843 ").

3 A.a.O., I 846 , Bd. IV, S. 305. 
Geschick der unteren Volksschichten in erster Linie nicht als ein Stand der Rechtlosigkeit oder der widerrechtlichen Ausbeutung erschienen ist, sondern als ein Stand minderer Sittlichkeit, dessen Angehörige von der Teilnahme an den Sphären höherer Sittlichkeit, d.h. an Staat und Gesellschaft, ausgeschlossen waren. Unter diesen Umständen mußte es ihm nicht so sehr auf eine Reform der politischen und gesellschaftlichen Ordnung ankommen, als vielmehr auf eine Reform des Bewußtseins, da Sittlichkeit, fortschrittliche Bildung und aufgeklärtes Bewußtsein einander bedingten. „Von der Reform der politischen Formen das Heil der Welt zu erwarten, ist der alte Fehler des Liberalismus; alles liegt an der Reform des Bewußtseins. Die Reform des Bewußtseins ist die Reform der Welt und kein Gott kann sie hindern". 1

Auf diese Weise gerieten die Forderungen nach geistiger und sozialer Befreiung in einen circulus vitiosus, da die Bildungsmöglichkeiten der Masse an den bestehenden sozialen Verhältnissen sehr schnell ihre Grenzen fanden, andrerseits aber die Befreiung aus diesen Grenzen ohne geistige Bildung nicht möglich sein sollte. Dieses Problem ist für einen jungen Mann, mit dem Ruge r 843 eine Periode engeren Einverständnisses durchlebt hat, zur entscheidenden geistigen Herausforderung geworden - für Karl Marx.

\section{VI}

Als Student in Berlin hatte Karl Marx in den Jahren um 1840 engen Anschluß an den dortigen Kreis der Junghegelianer gefunden und u.a. mit Bruno Bauer einen lebhaften Umgang gepflegt. Jedoch als er I842 die Stadt verlassen hatte und zunächst im Rheinland sowie anschließend in der Pariser Emigration lebte, schlug seine geistige Entwicklung eine eigene Bahn ein, die ihn nicht nur von seinen Berliner Freunden, sondern auch von allen übrigen Junghegelianern trennte. Der Gang dieser Entwicklung läßt sich recht gut daran beobachten, wie Marx die Rolle des Volkes, des Proletariats in Staat und Gesellschaft beurteilte.

Anfänglich war er wie seine junghegelianischen Gesinnungsgenossen vom spekulativen Staatsbegriff Hegels ausgegangen, wonach der Staat "die Wirklichkeit der sittlichen Idee" sei und alle einzelnen Menschen die „höchste Pflicht” hätten, „Mitglieder des Staates zu sein", da „das Individuum selbst nur Objektivität, Wahrheit und Sittlichkeit [habe], als es ein Gleid desselben ist". ${ }^{2}$ Dementsprechend

I A.a.O., I 846, Bd. III, S. I 1o (aus: „Selbstkritik des Liberalismus. I843”).

2 G. W. F. Hegel, Grundlinien der Philosophie des Rechts, Berlin 1956, S. 207 f. $(\$ \$ 257$ f.). 
hatte Marx warnend gegen einen Staat, der alles öffentliche Leben innerhalb seiner Grenzen unterdrückte, darauf hingewiesen, daß in ihm das Volk dem politischen Aberglauben anheimfallen oder aber, "ganz vom Staatsleben abgewendet”, zum „Privatpöbel” werden müsse. ${ }^{1}$ Noch gefährlicher für das Schicksal des Staates erschien ihm die wenig später wahrgenommene Lage der „untersten besitzlosen und elementarischen Masse", 2 deren Not er dem Staat als einem „weisen Gesetzgeber”, der „mit der höchsten Milde” diese „soziale Unordnung korrigieren" müsse, ${ }^{3}$ anempfahl. Zugleich umriß er den problematischen Tatbestand der sozialen Wirklichkeit treffend mit der Feststellung, daß „das Dasein der armen Klasse selbst bisher eine bloße Gewohnheit der bürgerlichen Gesellschaft ist, die in dem Kreis der bewußten Staatsgliederung noch keine angemessene Stelle gefunden hat", ${ }^{4}$ d.h. daß die unteren, armen Volksklassen weder sozial noch politisch integriert und dadurch zu einem Dasein der „Unordnung" verurteilt seien, das der Staat, wenn er seinem Beruf, die „Wirklichkeit der sittlichen Idee" zu sein, gerecht werden wollte, aufheben mußte. Marx war hier Realist und Idealist zugleich, denn er hatte seinen sozialkritischen Realismus noch mit einem politischen Idealismus verbunden, der auf den Staat als auf eine Kraft baute, die über den sozialen Gegensätzen stehen und sich als eine Sphäre der Freiheit bewähren sollte. Es mußte demnach alles darauf ankommen, ob der Staat dieser seiner Rolle gerecht werden würde oder nicht.

In dieser Hinsicht hatte die politische Entwicklung der Jahre I 842 und 1843 bewirkt, daß die Junghegelianer ihr Vertrauen in den ideellen, selbstlosen Charakter des Staates verloren hatten und die bestehenden Staaten von ihrem wahren, im Hegelschen Sinne verstandenen Begriffe weit entfernt sahen. Diese Erfahrung diente Marx als Anlaß dafür, kritisch zu prüfen, inwieweit der Hegelsche Staatsbegriff überhaupt mit der Wirklichkeit zu vereinbaren sei oder wie andrerseits die Verhältnisse tatsächlich beschaffen seien. ${ }^{5}$ Während dieser geistigen Auseinandersetzung ist für Marx die Lage der sozial deklassierten Massen zwar ein ständiger moralischer Ansporn gewesen, aber seine Aufmerksamkeit richtete sich dabei vorzugsweise auf die Stellung des Menschen schlechthin in der damaligen Gesellschaft, und erst die auf diesem Wege gewonnenen Einsichten ver-

1 K. Marx/F. Engels, Werke [= MEW], Berlin 1956, Bd. I, S. 64 (aus „Debatten über die Preßfreiheit", is. Mai i 842 ).

2 A.a.O., S. I I (aus: „Debatten über das Holzdiebstahlgesetz”, 25. Okt. I 842).

3 A.a.O., S. 120 (dto., 27. Okt. 1842).

4 A.a.O., S. 119 (dto.); ferner S. 284. Vgl. dazu W. Conze, „Vom 'Pöbel' zum 'Proletariat' ", in: a.a.O., S. $333 \mathrm{ff}$.

$5 \mathrm{Vgl}$. A. Cornu, a.a.O., S. 4r8ff. 
wertete er unmittelbar für eine weitere Ausgestaltung seiner Theorie der Massen.

Seine wesentlichste Entdeckung ist es gewesen, daß zwischen der Gesellschaft als bürgerlich-sozialer und dem Staat als politischer Daseinsform ein tiefer Unterschied bestehe ${ }^{1}$ und daß demzufolge der Mensch als Staatsbürger (citoyen) und als Glied der Gesellschaft (bourgeois) ein Doppelleben führe, ${ }^{2}$ wobei der erstere gegenüber dem letzteren für die wahre, allgemeine Form des Menschseins angesehen werde. ${ }^{3}$ Marx stellte fest, daß im Staat - und zwar den demokratischen Staat eingeschlossen - der Mensch wohl formell als das höchste Wesen anerkannt werde, daß aber darunter „der Mensch in seiner unkultivierten, unsozialen Erscheinung” verstanden werde, d.h. „der Mensch, wie er durch die ganze Organisation unserer Gesellschaft verdorben, sich selbst verloren, entäußert, unter die Herrschaft unmenschlicher Verhältnisse und Elemente gegeben ist, mit einem Wort, der Mensch, der noch kein wirkliches Gattungswesen ist". ${ }^{4}$ Das bedeutete, daß jede Emanzipation, die sich allein auf den politischen Bereich erstreckte, mit einer Täuschung enden müsse, da sie die sozialen Bindungen des Menschen unbeeinflußt lasse, wie z.B. die politische Revolution "das bürgerliche Leben in seine Bestandteile auf[löse], ohne diese Bestandteile selbst $\mathrm{zu}$ revolutionieren und der Kritik zu unterwerfen". 5 Damit war es auch ausgesprochen, daß vom Staate, der seinem Wesen nach stets eine politische Form der Organisation darstelle, die soziale Emanzipation der deklassierten Gesellschaftsschichten nicht zu erwarten sei und daß es zu diesem Zwecke viel weiterreichender Veränderungen bedürfe als sie bisher durchgeführt worden seien. ${ }^{6}$

An diesem Punkte angelangt, wurde es für Marx wichtig, die Träger jener neuen, radikalen Revolution zu bezeichnen und ihre Erfolgsaussichten abzuschätzen. Es war naheliegend, hierbei in erster Linie auf die Kraft derjenigen zu rechnen, deren Ansprüche zum Programm der Revolution werden sollten und deren vorläufige Daseinsweise als der schlagendste Beweis für die Unhaltbarkeit der bestehenden sozialen Ordnung angesehen werden konnte. So setzte Marx seine Hoffnungen auf die „Bildung einer Klasse mit radikalen

1 MEW, Bd. I, S. 272 und 286 (aus: „Kritik des Hegelschen Staatsrechts”, 1843).

2 A.a.O., S. 354 f. (aus: „Die Judenfrage”, I $843 / 44$ ).

3 Ebda. Vgl. A. Cornu, a.a.O., S. 43 if.

4 A.a.O., S. 360 (dto.).

5 A.a.O., S. 369 (dto.). Die Definition, die den Staat als Instrument der herrschenden Klasse bezeichnet, findet sich zwei Jahre später in der „Deutschen Ideologie”, MEW, Bd. III, S. 62.

B A. Cornu, a.a.O., S. 479 f. 
Ketten, einer Klasse der bürgerlichen Gesellschaft, welche keine Klasse der bürgerlichen Gesellschaft ist, ... welche nicht mehr auf einen bistorischen, sondern nur noch auf den menscblichen Titel provozieren kann,... welche mit einem Wort der völlige Verlust des Menschen ist, also nur durch die völlige Wiedergewinnung des Menschen sich selbst gewinnen kann. Diese Aufösung der Gesellschaft als ein besonderer Stand ist das Proletariat". ${ }^{1}$ „,Weil in den Lebensbedingungen des Proletariats alle Lebensbedingungen der heutigen Gesellschaft in ihrer unmenschlichsten Spitze zusammengefaßt sind, weil der Mensch ... durch die nicht mehr abzuweisende, nicht mehr zu beschönigende, absolut gebieterische Not . . zur Empörung gegen diese Unmenschlichkeit gezwungen ist, darum kann und muß das Proletariat sich selbst befreien". Das könne es aber nicht tun, ohne zugleich "alle unmenschlichen Lebensbedingungen der heutigen Gesellschaft, die sich in seiner Situation zusammenfassen, aufzuheben". ${ }^{2}$ Das alleinige Mittel zu diesem Zwecke sei die Revolution, da sich „ohne Revolution... der Sozialismus nicht ausführen" könne. ${ }^{3}$ Um die große Menge des Proletariats zur Erkenntnis ihrer Lage zu befähigen, aus der sie die Entschlossenheit zu revolutionären Taten gewinnen würde, verkündete Marx das Bündnis zwischen Geist und Masse, das auf der Vereinigung der forschrittlichen Denker mit dem Proletariat beruhen sollte. Zwar müsse „die materielle Gewalt . . . gestürzt werden durch materielle Gewalt, allein auch die Theorie wird zur materiellen Gewalt, sobald sie die Massen ergreift”, und so „wie die Philosophie im Proletariat ihre materiellen, so findet das Proletariat in der Philosophie seine geistigen Waffen"."

Damit war für Marx in formellem Sinne die Frage, wie die fortgeschrittene Theorie der Junghegelianer verwirklicht werden könne, beantwortet, und was nun noch blieb, das war die praktische Aufgabe, Geist und Masse in einen organisierten, handlungsfähigen Zusammenhang zu bringen. Das ist eines der Ziele gewesen, denen Marx fortan gelebt hat. Wie bereits gezeigt worden ist, hatte auch Ruge die Verwirklichung der Theorie von den Massen erwartet, jedoch hatte er sich mit allgemeinen Vermutungen begnügt und diesen Gedanken nicht näher ausgeführt. Anders tat es Marx, der

1 MEW, Bd. I, S. 390 (aus: „Zur Kritik der Hegelschen Rechtsphilosophie. Einleitung”, I 843/44). Über Marx' Begriff des Proletariats s. W. Conze, „Vom 'Pöbel' zum 'Proletariat'", in: a.a.O., S. 343 f., und K. Löwith, a.a.O., S. 266 f. Ferner M. Hellweg, Die Stellung des Proletariats bei Karl Marx, Frankfurt/M. 1947, S. Igff. Vgl. auch A. Cornu, a.a.O., S. 480 und 490 .

2 MEW, Bd. II, S. 38 (aus: „Die heilig Familie”, I 844).

3 MEW, Bd. I, S. 409 (aus : „Kritische Randglossen zu dem Artikel eines Preußen”, I844).

4 A.a.O., S. ${ }_{3} 85$ und $39 \mathrm{r}$ (aus: „Zur Kritik der Hegelschen Rechtsphilosophie. Einleitung" I $843 / 44$ ); vgl. auch S. $342 \mathrm{f}$. 
zwar ähnlich wie Ruge von einem allgemeingehaltenen Massenbegriff - „die unterste besitzlose und elementarische Masse” - ausgegangen ist, dann aber bald zu der Vorstellung fortgeschritten ist, daß unter der breiten Masse der Armen und Deklassierten eine Gruppe zu finden sei, die äußerlich den tiefsten Stand der Entpersönlichung und Vermassung darstellen, jedoch durch die ins Unerträgliche gesteigerte Trostlosigkeit ihres Daseins denjenigen Punkt erreiche, an dem die bloße Quantität der Masse in die neue Qualität einer revolutionären Klasse umschlage. Diese Gruppe war ihm das industrielle Proletariat, das er seinen Ursprung nach als eine ",künstlich produzierte Armut” von der naturwüchsigen, "mechanisch durch die Schwere der Gesellschaft niedergedrückten" Armut unterschied, ${ }^{1}$ und dem er den Beruf zuschrieb, an die Spitze der sozialen Emanzipationsbestrebungen zu treten „und die ganze Masse mit sich fortzureißen".2

Aus alledem ist zu entnehmen, daß Marx den unbestimmten, verallgemeinernden Massenbegriff überwunden und durch einen soziologisch begründeten ersetzt hatte. Die abstrakt psychologische Betrachtungsweise, deren sich Bruno Bauer befleißigt hatte, war von ihm entschieden zurückgewiesen worden, da sie an die Stelle der Wirklichkeit ein willkürlich zurechtgestutztes Zerrbild setze. ${ }^{3}$ Ferner war ihm die Verachtung, die von bildungsstolzen Intellektuellen den geistlosen Massen erwiesen wurde, fremd und wurde von ihm durch den Willen zum Bündnis mit der Masse ersetzt. Der Gegenstand seines Massenbegriffs waren die in Armut und Rechtlosigkeit lebenden Volksschichten, deren Existenz er als eine Herausforderung des sozialen Gewissens empfand. Weit entfernt davon, sich mit dem unmenschlichen Dasein dieser Menschen abzufinden, lenkte er sein Streben darauf, den festgestellten Übeln abzuhelfen. Anfänglich rechnete er dabei auf das Verantwortungsbewußtsein des Staates, aber mit der Erkenntnis, daß Staat und Gesellschaft nicht das Ergebnis idealer philosophischer Konstruktionen, sondern miteinander rivalisierender sozialer Gruppen seien, gab er das Vertrauen auf eine Hilfe, die den Massen von außen her zuteil werden könnte, auf und entwickelte statt dessen die Theorie, daß die Masse - zumal in der Form des Proletariats - berufen sei, sich selbst zu helfen. Damit war zugleich der negative Massenbegriff, der von der Vorstellung eines gestalt-,

\footnotetext{
A.a.O., S. 390 f. (dto.). Uber Proletariat und Pauperismus vgl. auch MEW, Bd. III, S. 183 .

2 MEW, Bd. III, S. 6r (aus: „Die deutsche Ideologie”, r845/46).

3 MEW, Bd. Il, S. 164 (aus: „Die heilige Familie”, I 844): „Die Masse, wie sie Gegenstand det kritischen Kritik ist, hat nichts gemein mit den wirklichen Massen, die wieder sehr massenhafte Gegensätze unter sich bilden." Vgl. S. 88.
} 
geist- und kraftlosen Pöbels ausging, abgetan; an seine Stelle trat der Gedanke, daß die deklassierten Volksschichten nicht dazu bestimmt seien, um die kärgliche Mildtätigkeit einer Gesellschaft, von deren Annehmlichkeiten sie ausgeschlossen waren, zu betteln oder um eine Einordnung in diese Gesellschaft nachzusuchen, sondern daß sie berufen seien, als der größere und wahrhaft menschliche Teil der Menschheit eine neue Ordnung zu schaffen, in der jede Art der Ungleichheit ausgeschlossen sein würde. War bei Hegel die Entstehung der Masse als das unvermeidliche Ergebnis der zu Überproduktion und Kauf kraftverlust verurteilten bürgerlichen Gesellschaft angesehen worden, ohne daß daraus Konsequenzen für die Zukunft dieser Gesellschaft gezogen wurden, so erblickte Marx in der Masse nicht nur das Ergebnis, sondern auch das unvermeidliche Schicksal der bürgerlichen Gesellschaft, indem er von der besonderen Lage auf eine besondere Sendung der Masse schloß. Hierbei kam ihm seine soziologisch-kritische Beobachtungsgabe zugute, die ihn über die Gesichtspunkte Hegels und solcher Zeitgenossen wie Ruge und Bauer hinausgelangen ließ; aber gleichzeitig verwandte er die kritisch gewonnenen Einsichten als Grundlage für eine optimistische, ideologisch überhöhte Theorie der Massen, die an Leidenschaft und geistigem Aktivismus alle konkurrierenden Theorien übertraf.

\section{VIII}

Im Anschluß an die bisherigen Ausführungen bedarf es keines weitläufigen Beweises, um zu zeigen, daß der Begriff Massenpsychologie unzureichend ist. Nach dem aufsehenerregenden und namengebenden Buch Le Bons ist dieser Begriff zwar üblich geworden, aber bereits hier hatte es sich um mehr gehandelt als um eine Psychologie der Massen, da Le Bon in Verbindung mit geschichtsphilosophischen und kulturkritischen Gedankengängen seine Überlegungen zu einer vielseitigen Theorie der Massen ausgeweitet hatte, die gerade dank ihrer Vielseitigkeit die bekannte Wirkung erzielen konnte. Es ist deshalb angemessener, in diesem Zusammenhange von "Theorie der Massen” $\mathrm{zu}$ sprechen, da dieser Ausdruck allgemeiner und umfassender ist. ${ }^{1}$

Ein Überblick über die Entwicklung der Theorie der Massen bei Hegel, den Junghegelianern und bei Le Bon kann davon ausgehen, daß die Masse für das ganze 19. Jahrhundert eine bekannte, wenn auch anfangs in ihrer besonderen, durch die Industrialierung bedingten Form wenig vertraute Erscheinung gewesen ist. Ebenfalls in die

1 Eine konkrete und dem Sinngehalt ihres Begriffs entsprechende Anwendung der Massenpsychologie gibt K. Baschwitz, a.a.O., S. $82 \mathrm{ff}$. 
erste Hälfte des genannten Jahrhunderts reicht die Verbindung zurück, die zwischen dem Auftreten der Masse und den Äußerungen eines allgemeinen Krisengefühls zu beobachten ist, so daß alle Theorien der Massen gleichzeitig als Theorien der Krise bezeichnet werden können.

Am wenigsten ist sowohl von dem einen wie vom andern bei Hegel die Rede gewesen. Er ist zwar Realist genug gewesen, die beunruhigenden Phänomene der Masse, die mit dem Aufkommen neuer Prinzipien auf politischem und sozialem Gebiet verbunden waren, zu erkennen, jedoch hat er sie nicht für so unaufhaltsam angesehen, daß sie als eine zukunftsträchtige Realität hätten gewürdigt werden müssen. Die Masse blieb ihm eine Erscheinung am Rande der vernünftig geordneten Welt und war als solche für ihn existent, jedoch ohne wesentliche Bedeutung.

Das Gefühl der Selbstsicherheit, das Hegel bei der Behandlung der Masse an den Tag gelegt hatte, trat bei seinen jüngeren Anhängern, den Junghegelianern, bereits in sehr veränderter Gestalt auf. Wohl haben sie persönlich in allen Situationen ein großes Selbstvertrauen bewiesen, aber gänzlich geschwunden war bei ihnen das Vertrauen auf den Fortbestand der überkommenen gesellschaftlichen und staatlichen Ordnung. Statt dessen bekannten sie sich zu der Auffassung, daß ihre Zeit eine Epoche der großen Krise sei, von der alle menschlichen Daseinsformen einen Wandel erfahren würden. Unter diesen Umständen maßen sie dem Vorhandensein der Massen als einem Symptom des sichtbaren Verfalls von Staat und Gesellschaft eine besondere Bedeutung bei und konnten sie entweder - wie Bauer als die überständige, negative Verkörperung des Zeitalters schlechthin oder - wie Marx - in ihrer qualitativen Verdichtung des Proletariats als den schöpferischen Träger einer epochalen Wende in der Geschichte der Menschheit bezeichnen. Gemeinsam war beiden Standpunkten jedoch das positive Krisengefühl, das mit einem bedeutenden Fortschritt des Menschen als Ergebnis der allgemeinen Erschütterung rechnete.

Anders war es fünfzig Jahre später bei Le Bon, dem die konstatierte Krise der Gesellschaft und Kultur zur Grundlage pessimistischer Stimmungen wurde, in denen sich die Haltung jenes konsequenten, um seine Existenzfreiheit besorgten Individualismus fortsetzte, wie sie unter den Junghegelianern D. F. Strauß vertreten hatte. Die sozialen Veränderungen wurden jetzt nicht mehr als die Anzeichen einer besseren Zukunft, sondern als die Todesboten einer sterbenden Kultur gedeutet. Dementsprechend verwandelte sich die Theorie der Massen in eine negative Prognose der weiteren Entwicklung, in der 
- je nach Temperament - gelassener Fatalismus oder leidenschaftliche Empörung bestimmend sein konnten.

Der große Unterschied, der zwischen der Haltung Le Bons und der der Junghegelianer bestand, ist auf die von einander abweichende geschichtsphilosophische Grundlegung der beiderseitigen Ansichten zurückzuführen. Es zeigt sich in diesem Falle, daß Geschichtsphilosophien ihr Gewicht nicht nur durch die ordnende Kraft, die sie gegenüber dem Stoff der Vergangenheit beweisen, erhalten, sondern auch durch die scheinbar empirischen Prämissen, die sie den Spekulationen über die Gegenwart und Zukunft liefern. Was Hegels dynamische, fortschrittsorientierte Geschichtsphilosophie betrifft, so beflügelte sie ihre Anhänger zur Vision neuer Fortschritte und damit zu einer optimistischen, erwartungsvollen Haltung gegenüber der Zukunft. Sichtbarstes Beispiel ist hierfür das Sendungsbewußtsein Karl Marx' und der unter seinen Einfluß geratenden Arbeiterbewegung.

Im Gegensatz dazu war das zyklische Geschichtsbild, zu dem sich Le Bon bekannte, geeignet, allen zukunftsfrohen Optimismus auf doppelte Weise zu dämpfen. Einmal setzte sie durch die Vorstellung von der periodischen Wiederkehr früherer Entwicklungsstufen die Bedeutung jedes erzielten Fortschritts herab und zum andern unterstrich sie mit der Verheißung eines unvermeidlichen Endes der einzelnen Kulturen die zeitliche Begrenztheit aller kulturellen Errungenschaften. Wenn dazu noch, wie bei Le Bon, das Bewußtsein hinzukam, am Ende eines historischen Zyklus zu stehen, dann konnte das Krisengefühl jene Formen der Passivität und des Fatalismus annehmen, die Le Bon so nachdrücklich von den Junghegelianern trennten. Während diese sich angeschickt hatten, eine neue Welt zu erobern, hat jener alles verloren gegeben, nicht zuletzt in Gestalt einer Kapitulation vor den Kräften, denen Karl Marx durch seine Theorie der Massen Selbstbewußtsein und Stoßkraft verliehen hatte. Auf diese Weise haben die einzelnen Phasen in der Entwicklung der Theorie der Massen aufeinander eingewirkt, wie sie denn überhaupt durch die Tatsache, daß beide den Massen eine besondere historische Sendung zuschreiben - sei sie positiver oder negativer Art -, letzten Endes einander näher stehen, als es auf den ersten Blick den Anschein hat. Aber gerade diese Vorstellung von der Sendung der Massen hat erst überwunden werden müssen, ehe aus den weltanschaulich beschwerten Theorien der Masse eine unbefangenere Sozialpsychologie des kollektiven Verhaltens werden konnte. 